Departamento de Anatomia Descritiva dos Animais Domésticos Direlor: Pror. Dr. M. Barros Erhart

Departamento de Indústria, Inspeção e Conservação dos Produtos Alimentares de Origem Animal Dirctor: Prof. Dr. Paschoal Mucciolo

\title{
DISTÂNCIA DO TORUS PYLORICUS Á PAPILLA DUODENI HEPATICA EM BOUINOS MESTIÇOS DE ZEBU
}

(Estudo estatístico sobre 411 observações) *

(DISTANCE FROM THF TORUS PYLORICUS TO THE PAPILLA DUODENI HEPATICA IN BRAHMAN CROSSBREDS)

(Statistical study of 411 observations)

\author{
Orlando M. Paiva e Paulo de Assis Ribeiro \\ Assistentes \\ 2 grificicos no texto
}

Segundo nos dá conta THomson (1940 a), em interessante resenha histórica, as primeiras observações respeitantes aos tractos biliares extra-hepáticos parecem ter sido registradas, há séculos, ao tempo da fundação legendária de Roma, na interpretação do sacrifício dos animais.

Embora, a partir dessa época, o acervo de investigações dedicadas ao estucio clas vias excretoras da glândula hepática tenha-se avolumado, incessantemente, reconhece-se ainda hoje, e talvez por muito tempo se possa sustentar tal parecer, que os conhecimentos sôbre aquêle capítulo da morfologia comparativa são incompletos estando a merecer o suplemento de novas contribuiçōes. Prova-o o fato de desconhecermos quaisquer dados sôbre a distância do piloro à papila duodenal maior, $\mathrm{cm}$ bovinos mestiços de Zebu (Bos indicus), assunto de que se ocupa a presente pesquisa.

Meio ao considerável número de $\mathrm{AA}$. apontados pelo próprio THOMSON (1940 b), em ulterior publicação, como tendo colaborado, sucessivamente, para o conhecimento das vias biliares extra-hepáticas no homem e em várias espécies animais, tanto do ponto de vista anatômico quanto do fisiológico, importa destacar MANN, BRIMHALL e Foster (1920), ManN, Foster e Brimhall (1920) e Thomson (1938), pelas indicações contidas em seus trabalhos, concernentes à distância do piloro à abertura do ducto colédoco em animais.

Dados anátomo-comparativos sôbre a referida distância encontram-se, igualmente, em BAUMANN e SCHMOTZER (1912), STEvenson 
(1921), Favilli (1923), Higgins (1927), Schäppi (1931), FGLI (1935), Silva Pinto (1933), Delprato (1938) e, por fim, no já mencionado THOMSON (1940 b).

Da série de contribuições compulsadas, todavia, selecionámos e resumircmos a seguir appenas as que encerram observaçōes relativas à localização da abertura do ducto biliar no duodeno de bovinos, pois, o presente estudo, como $\mathrm{cm}$ parte se adiantou, tem por escopo estabclecer e analisar, estatisticamente, a condiçño anatômica média concernente à distância, em centímetros, da extremidade intestinal do Torus pyloricus à desembocidura do Ductus choledochus, em mestiços de Zebu, entro a primeira e última mudas, ou seja, com idades variáveis de 28 a 51 meses aproximadamente.

BaUmanN e SCIMotzea (1912) apresentam importante contribuição para a anatomia comparativa da ampola de Vater e dá abertura dos ductos excretores das glânáulas hepática e pancréática, estudando as disposicốcs correspondientes aos eqüinos, bovinos, ovinos, porcinos, caninos, felinos c às aves domésticas. A investigação abrange aspectos macro- e microscópicos daquelas estruturas, constituindo documentário de funclamental proveito para o objetivo que temos em mira. Efetivamente, meio às observações fixadas sob o título bovinos, ensina-se: o ducto co'édoco abre-se na segunda flexura da alça duodenal, à distância de $50-70 \mathrm{~cm}$ ro piloro. No tracto intra-parietal, de $2-3 \mathrm{~cm}$, o diâmetro do ducto atinge de $9-10 \mathrm{~mm}$, enquanto, o diâmetro do intestino, neste ponto, alcança de $3-1.5 \mathrm{~cm}$.

O ducto colédoco atinge o duodeno, quase perpendicularmente; muda, então, de direção e penetra na parede intestinal seguindo trajeto oblíquo. No lado da penetração, a luz intestinal mostra saliência alongada, a Papille drodeni, com $6-8 \mathrm{~mm}$ de comprimento e aproximadamente a mesma altura. Em casos isolados, o ducto excretor alarga-se, muito pouco, na papila c depois estreita-se, outra vez, na desembccadura; este alargamento é. todavia, insignificante para que possa ser comparatlo à ampola de Vater.

Em tabela ancxa, os AA. agrupam as medidas corresponclentes à distância do piloro is Pagilla dizodeni, nos 8 casos estudados (59.062.5-68.0-51.5-69.5-53.0-52.0 e $67.0 \mathrm{~cm}$, e indicam a resjectiva média: $60.7 \mathrm{~cm}$. As médias relativas às distancias do piloro à Prapilla pencreatica $(9: .4 \mathrm{~cm})$ e interpapilar $(32.6 \mathrm{~cm})$ são também assinalarlas.

Nas restantes esirécies domésticas, segundo BAUMANN e SchmotZER, as distâncias do piloro à ampola de Vater c à abertura do colédoco seriam: cquiinos, $16.0 \mathrm{~cm}$; ovinos, $43.0 \mathrm{~cm}$; poicinos, $3.0 \mathrm{~cm}$; caninos, $6.1 \mathrm{~cm}$; felinos, $3.2 \mathrm{~cm}$; aves, $30.0 \mathrm{~cm}$. 
BLANN, BrimenLl e Foster (1920), em trabalho de igual interêsse para nós, realizam o estudo do tracto biliar extra-hepático em 11 espécies animais providas de vesícula biliar e em 4 outras carecentes dêste órgão, com o objetivo precípuo de indagar: a) se o tracto biliar extra-hepítico compensa a lalta de vesícula biliar; b) se existe relação entre a presença e ausência dêste órgão e a clistância que separa o pilcro do ponto de abertura, no duodeno, do ducto biliar comum. A resposta é negrativa em ambos os casos. Antes de chegarem a egias conclusóses, todavia, os AA. reconhecem dificuldade em obter dados sôbre as partes componentes do tracto biliar em anatomia comparativa e propōem-se, entre outros itens, a verificar a distância do piloro à entrada do ducto biliar comum. Foram estudadas as seguintes espécies domésticas: bovina, ovina, caprina, canina, felina e leporina, tendo sido reunitos 5 exemplares de cada uma, apresentando aproximadamente o mesmo tamanho. O cavalo também foi estudado, embora não incluido em tabela anexa, na qual se agrupam as medidas tomarlas. Nas 5 vacas examinadas, anotaram-se as seguintes dimensões relativas à distincia do piloro à abertura do ducto biliar comum: $500-550-$ $575-575-550 \mathrm{~mm}$. Entre os dados anátomo-comparativos registiam-se, para cs bovinos, os seguintes: vesícula biliar bem desenvolvida; ducto biliar comúm, longo, com bom diâmetro; ducto cístico longo; distância de abertura do ducto biliar, longa. Por outro lado, os AA. citam no texto que, nos bovinos, o ducto hepático penetra entre 50 e $70 \mathrm{~cm}$, reproduzindo, provàvelmente, os dados divulgados pelos tratadistas.

ManN, Foster e Brimirall (1920) procuram estabelecer a relação entre o ducto biliar comum e o ducto pancreático, em animais domésticos e de laboratório. O estudo de 15 espécies permite discriminar três grupos, no primeiro dos quais, o mais simples, classificam-se o boi, o porco, o coelho, a cobaia e o "striped gopher" (C. tridemlineatus); neste grupo, ambos os ductos entram no duodeno através aberturas isoladas.

Os A A. ilustram, esçuemàticamente, a disposição correspondente àqueles condutos excretores nos bovinos, apondo a cada um dêles as sesruintes !cgendis: abertura do ducto biliar ecmum a $575 \mathrm{~mm}$ do piloro; abertura do ducto vencreático a $875 \mathrm{~mm}$ do piloro.

FAvildi (1923), em monografia sôbre a anatomia do figado de alguns dos animais domésticos (cavalo, boi, porco, cão) explica: o colécoco, nos bovinos, attravessa a parede intestinal a discreta distância do piloro e isoladamente; a distância varia entre 3 decímetros (LAvocat) e 6 ou 7 decímetros (COLIN). O ducto excretor pancreá- 
tico desemboca, a jusante do colédoco, a cêrca de $30 \mathrm{ou} 40 \mathrm{~cm}$ do ponto de abertura dêste.

Delprato (1938), descrevendo, nos bovinos, as vias biliares extra-hepáticas e suas variações assinala, ao apreciar o trajeto e direção do colédoco, que êste segue a princípio a direção do conduto hepático, ou seja, orienta-se obliquamente de baixo para cima e da esquerda para a direita, chegando ao duodeno, onde termina na face inferior da segunda curvatura, ao nivel dum espessamento da mucosa, em forma de papila, situado a uns 60 a $70 \mathrm{~cm}$ do piloro.

THOMSON ( $1940 \mathrm{~b}$ ), por fim, em contribuição ì anatomia das vias biliares extra-hepáticas nos mamíferos, passa em revista as ordens Marsupialia, Primata, Edentata, Rodentia, Carnivora, Cetacen, Hyracoidea, Sirenia, Perissodactyla e Artiodactyla. Entre os Artiodactyla estuda os ovídeos (Ovis aries), os bovídeos (Bos taurus) e os suideos (Sus scrofa domestica), enquadrando suas apreciações nos quatro itens seguintes : a) presença ou ausência da vesícula biliar; b) relação entre o ducto lepático comum (quando não há vesícula biliar) e o ducto pancreático; c) presença da papila ducdenal; d) distância da abertura do ducto biliar, a partir do piloro; e) relação dos estudos do A. com a literatura a respeito do tracto biliar extra-hepático. Dentre êstês, interessa-nos ressaltar as conclusões que se alinham no terceiro item.

Com referência à distância de abertura do ducto hiliar, o A. se expressa em têrmos médios toda vez em que o número de observacōes se baseia em duas ou mais medidas. Os resultados consignados para a distância do piloro à abertura do ducto colédoco, em mamíferos domésticos, são:

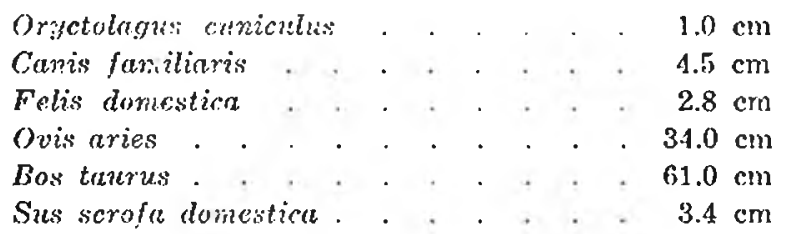

O A. chama atenção para a marcada diferença notada em espécies de Artiodactylla, com vesícula biliar; nos bovinos, a abertura está situada a $61 \mathrm{~cm}$ do piloro; nos suinos, $3.4 \mathrm{~cm}$ caudalmente ao mesmo ponto de reparo. O comprimento do intestino delgado dos bovinos é aproximadamente três vêzes maior do que o dos suinos, esclarece o $\mathrm{A}$.

As anotações concernentes aos bovinos, estabeleceu-as THOMSON baseando-se nos sete exemplares reunidos para estudo; reproduzamolas: vesícula biliar grande e piriforme; parede firme; frouxamente ligada ao fígado por tecido conjuntivo; ductos passando diretamente 
O. M. Paiva e P. de A. Ribeiro - Vias bil. extra-hepát. em mest. de Zebu

do parenquima hepático às paredes da vesícula biliar; o ducto biliar comum abre-se no duodeno, em papila localizada $61 \mathrm{~cm}$ caudalmente ao piloro; o ducto pancreático abre-se separadamente no duodeno.

Expostos, assim, os escassos dados anátomo-comparativos sôbre as vias biliares extra-hepáticas, coletados mediante revisão da literatura, apresentamos as consideraçōes que os tratadistas tecem a respeito da localização da papila duodenal maior.

Mongiardino (1903), descrevendo o colédoco do boi, limita-se a expor sua disposiçāo ordinária em relação ao conduto pancrcático, ao qual não se une antes de desembocar no duodeno, comportamento aliás diverso do verificado nos jequemos ruminantes.

CARADONNA (1909), in BUSSI-CARADONNA, estuda, minuciosamente, as vias biliares extra-hepáticas, mas, não apresenta dados numéricos rclativos à situação da abertura do colédoco na superfície da mucosa do intestino delgado.

MONTANÉ-BourdFule (1917), no tomo II de seu tratado, dedicado ao estudo dos ruminantes, afirmam que o canal colédoco, com 6 a $8 \mathrm{~cm}$ de comprimento, abrc-se isoladamente, no intestino, a $65-70 \mathrm{~cm}$ do piloro. Causa certa surpresa, entretanto, o fato dos mesmos AA., sem esclarecerem devidamente a discordância numérica, ao se referirem páginas antes às aberturas do colédoco e do canal de Wirsung, tratando da superfícic interna do intestino de!yardo, escreverem que as citadas aberturas sĩo distantes, encontrando-se a primcira a $60-75 \mathrm{~cm}$ do piloro, a segunda a $35-40$ ou $60 \mathrm{~cm}$ alćm da última. Os valores extremos sāo, como se observa, afastados num total de $10 \mathrm{~cm}$ exatos.

LirovthF (1921) pronuncia-se simplesmente a propúsito: o canal excretor do fígado abre-se nos bovinos, isoladamente, a grandc distância do piloro ( $60 \mathrm{~cm}$ e mais).

LFSBLE (1922) nenciona ser grande a distância entre o piloro e a terminaçio isolada do cunal colédoco no duodeno e indica os valores de $62-75 \mathrm{~cm}$, assinalados em duas fêmeas por Colin. Fmbora tal idéia näo esteja expressa, é de se supor que êstes dados correspondam ans valores extremos anotados por Colin.

M.irtin-SCinuner (1935) esclarecem que os condutos excretores do fígado e do pintineas abrem-se, distalmente à flexura portal do duodeno, apartados do piloro, aquêle de $50-70 \mathrm{~cm}$, êste de $80-110 \mathrm{~cm}$. O A. confirma páginas adiante os mesmos dados, leferindo-se ainda à existência, de quando en quando, de um segundo conduto excretor do pânereas reunido an ducto colćdoco.

CMAMONNA (1929), in ZrMmbrl, citando Colin, assevera apenas: o colidoco vem alurir-se no intestino, isoladamentc, na ampola do Vater, à distûncia de $62-75 \mathrm{~cm}$ do piloro.

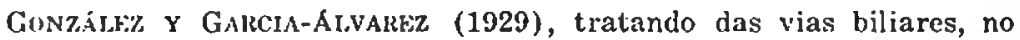
capitulo destinado ao estudo dos caracteres diferenciais do fígado nas espécies domésticas, admitem que, nos ruminantes, nos suinos e nos carnívoros, o conduto colédoco se apresenta com disposição parecida. Nos bovinos, ele termina no intestino, independentemente, à distincia de $62-70 \mathrm{~cm}$. 
FAviri, (1931) descreve o ducto cxcretor do ficado como atravessando as paredes do duodeno, a discreta distância do piloro, entre 30 e $70 \mathrm{~cm}$ e isoladamente.

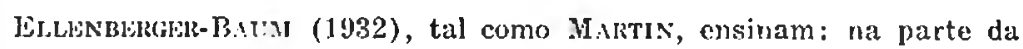
flexura portal do duorleno, ascendente em diveçio à coluna vertebral, dăo entrada os condutos excretores do figado o do pincicas, scparadamente, 0 primciro a $50-70 \mathrm{~cm}$, o segundo a $80-110 \mathrm{~cm}$ do viloro.

Sissox (1932) e Sisson-Grossmin (1945) são unânimes quando acentuam ser o ducto biliar curto, nos bovinos, penetrando na segunda flexura da curva em $S$ do duodeno, ou seja, em ponto situado a cêrca de $60 \mathrm{~cm}$ do piloro.

Bruni-ZimmerL (1947), estudando as vias biliares extra-hepúticas dos bovinos, adiantam que a abcrtura do colédoco no duodeno se dà à distancia de 60-75 cm do piloro e muito antes da desembocadura do conduto pancreático.

No quadro abaixo reunimos, resumindo, es dados numéricos extraidos da literatura especializada e os indicados pelos tratadistas, relativos às observaçōes levadas a cabo nos bovinos em gera!, determinando a distância, em centímetros, do piloro à abertura do ducto biliar comum: .

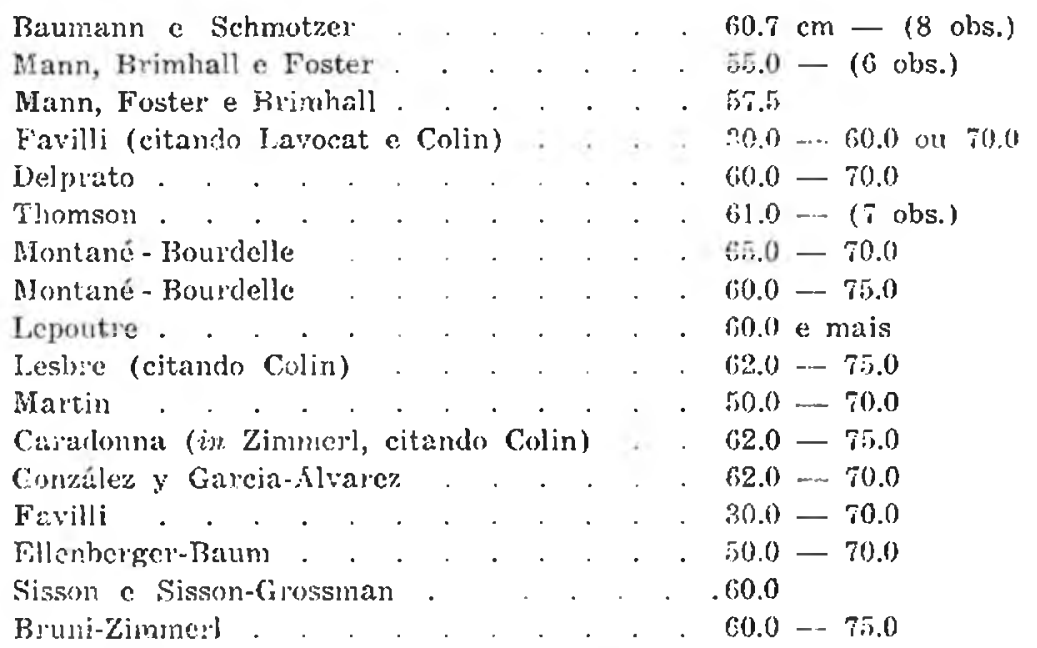

Material e método - As pesquisas relativas ì distância do piloro à abertura do ducto biliar, foram conduridas sôbre mais de 4 centenas de peças obtidas no Frigorífico Armour dà Capital de São Paulo.

Quem tenha acompanhado a rotina da sa!a de matança de qualquer grande matadouro, compreenderá imediatamente as dificuldades a superar, quardo a par da simples colheita de matcrial, sc intenta reu- 
nir dados sôbre sexo, idade e raça. Basta que se esclareça ser ocupação para equipe, pôsto tratar-se de trabalho a realizar-se separadamente, em pontos afastados na ampla sala de matança, e com a necessária destresa, para não perturbar o andamento quase cronométrico dos servicos. Assim, a um tempo se procedia a exame das carcassas, para verificação de raça, sexo, anotação do respectivo número e à leitura da mesa dentária, em cabeças isoladas, para determinação da idade, enquanto de outra parte, as peças iam sendo retiradas e recebendo número igual ao da própria carcassa, para ulterior identificacão. Este plano de trabalho nem sempre pôde ser executado à risca: algumas peças foram inutilizadas em benefício da rapidez de serviço imposta pelas circunstâncias, por isso, das 423 recolhidas para estudos, aproveitámos $411 \mathrm{em}$ condições de exame; destas, 312 provinham de machos, castrados em sua maioria, 14 de fêmeas, podendo admitir-se como provável que os restantes 85 animais fornecedores das mais peças fussem, na quase totalidade, machos, pois, o sacrifício de fêmeas na ocasião era esporádico, devido a restrições legais vigentes.

A idade dos animais oscilava entre os seguintes limites: os mais novos já mostravam substituição das pinças (cêrca de 2.8 meses) e os de idade mais avançada apenas iniciavam o desæraste dos cantos (51 meses aproximadamente), de acôrdo com os dados tabelados por Chiefri, Paiva e Veiga (1918) para raças indianas.

As peças recolhidas correspondem ao tracto duodenal de intestinos de bovinos mestiços de Zebu - cujas carcassas exibem características inconfundíveis e reconhecíveis à simples inspeção - tendo sua retirada, praticada pelos mesmos indivíduos, obedecido a critério uniforme, sempre rigorosamente seguido. Para tanto, praticavam-se duas secçōes: a primeira, proximal, realizava-se acima do orifício pilórico, em plena iegião pilórica do abomaso; a seguncla, distal, fazia-se aproximadamente de 90 a 120 centímetros alćm daquele mesmo ponto de reparo. Assim limitada a peça, o isolamento era completado mediante corte justa-duodenal do pequeno omento e mesc-duodeno em tôda a

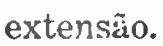

Transportado para o laboratório, o material assim recolhido era no mesmo dia preparado e posto em condiçōes de ser submetido às aprecią̧õcs anatômicas objetivadas.

Desfeitas cuidadosamente tódas as pregas da túnica serosa do segmento duorlena! e particularmente as flexuras portal -- ao nível da qual se abre no duodeno o ducto biliar - e ilíaca, abria-se o duodeno em todo o comprimento, procurando acompanhar o contóno da grande curvatura ou margem livre do órgão. A superfície da mucosa 
duodenal era então desembaraçada fàcilmente dos resíduos alimentares, mediante jacto de água sob pequena pressão.

Preparadas desta maneira, aos grupos de 20 ou 30, à proporção que chegavam do matadouro, as peças eram imersas em solução formolada a $10 \%$, ai permanecendo pelo espaço de 72 horas; decorrido êste tempo, processava-se a mensuração.

Dentre as 411 peças, todavia, separámos ao acaso, dos diferentes lotes, alguns duodenos, de maneira a reunir grupo de 164 peças 144 provenientes de machos, 20 de animais cujo sexo não se pôde averiguar - nas quais as dimensões foram tomadas a fresco e depois da fixação, não só para obter a média em material naquelas condições, como também para cálculo da retratilidade.

Exponhamos agora o critério adotado para medida de tôdas as peças, já que reputamos questão essencial para a apreciação dos resultados e confronto com os de outros AA., a indicação precisa das condições de obtenção dos dados.

Após fixação, os duodenos eram aplicados a plano horizontal e o suficientemente distendidos para que as dobras normais e eventuais da parede intestinal pudessem ser desfeitas. Estabelecemos então dois pontos de reparo sôbre a superfície da mucosa: um pilórico, papilar o outro; o primeiro, correspondendo à extremidade intestinal do Torus pyloricus, o segrundo, ao centro geométrico do contôrno circular da papila duodenal maior, ou, quando a abertura papilar se apresentava em fenda, a meia distância entre as comiscuras. A medida, tomada diretamente, era conseguida com facilidade, por meio de régua, à qual adaptámos duas hastes de madeira, uma fixa, a outra móvel, aplicando-se a haste fixa ao ponto pilórico e a móvel ao papilar. A medida, sempre tomada por um de nós (PAIVA), era repetida 3 vêzes, anotando-se a dimensão equivalente à média aritmética dos resultados.

Embora cercando a pesquisa ideada dòs indispensáveis rigores que devem nortear, especialmente, estudos da natureza do óra empreendido, descendo à minúcia para obtenção uniforme de valores em material homogêneo, fôrça é ver nos valores apresentados, a condição anatômica média; efetivamente, se nos foi inviável operar com animais do mesmo pêso relativo, devemos confessar também a impossibilidade de despistar algumas causas de êrro que devem ter interferido, inevitàvelmente, com maior ou menor intensidade, na exatidão dos dados; dentre essas causas, citaremos: estado de contratilidade da túnica muscular; variabilidade de retração sob a ação do formol; procedência dos animais de zonas diferentes do Brasil, etc.. 
Aos dados obtidos foram aplicadas as fórmulas para determinação da média aritmética, para dedução do êrro da média e do "t test", completando-se a análise estatística com a representação gráfica da distribuição por freqüuências das peças fixadas e frescas, acompanhadas das respectivas curvas teóricas, afim de estabelecer a classe modal ou normal e a própria norma, por outras palavras, o valor mais denso, que é, em todo o caso, na biologia e principalmente na medicina clínica, o melhor valor diretivo, o ponto de partida natural quando se trata de distribuição assimétrica, segundo afirma liAUTMANN (1921). $\left({ }^{*}\right)$

\section{RESUITADOS}

Foram, como se afirmou, preparadas 411 peças que, submetidas à mensuração, de acôrdo com o critério exposto, apresentaram os seguintes valores para a média e respectivo êrro padrão: 40.41 土. 0.31 $\mathrm{cm}$. Os números extremos encontrados, limitando amplitude total equivalente a $33.12 \mathrm{~cm}$, foram 25.78 e $58.90 \mathrm{~cm}$. O coeficiente de variabilidade atingiu a $15.59 \%$. Este, pois, o resultado geral fornecido pelas peças após fixação. Entretanto, havíamos de início resolvido separar do total de 411 duodenos destinados à pesquisa, ao acaso e de diferentes grupos para que a amostra fosse bem representativa, certo número de peças sôbre as quais duas medidas se efetuaram: a primeira prèviamente e a seģunda posteriormente à fixação. Ao realizar tal cotejo, outro não poderia ser o propósito $\mathrm{em} \mathrm{mira,} \mathrm{senão} \mathrm{o} \mathrm{de}$ assentar um índice de retratilidade dos tractos duodenais sob a ação do formol, que, eventualmente, viesse a ser aplicável à média global, para a partir de material fixado se poder ajuizar qual seria o valor teórico previsivel em peças frescas.

Com efeito, antes de submetê-las à fixação, 164 peças foram medidas e anotados os correspundentes números; permitiu-nos tal procerlimento, estabelecer os seguintes dados para a distância da extremidade intestinal do Torus pyloricus à abertura do Ductus choledochus: $45.02 \pm 0.49 \mathrm{~cm}$, estando as ouservaçoes disiribuidas entre os valores extremos 33.10 (2 casos) e $67.20 \mathrm{~cm}$, conseqüentemente numa amplitude de variação de $34.10 \mathrm{~cm}$. O coeficiente de variabilidade foi encontrado igual a $13.85 \%$.

As características estatísticas mais importantes dos valores assinalados para as mesmas 164 peças após 72 horas de fixação foram: $40.63 \pm 0.48 \mathrm{~cm}$ (média aritmética e êrro padrão da média), sendo a amplitude de variação de $29.90 \mathrm{~cm}$, com os valores extremos de 29.00 e 58.90 cm e o coeficiente de variabilidade igual a $15.21 \%$.

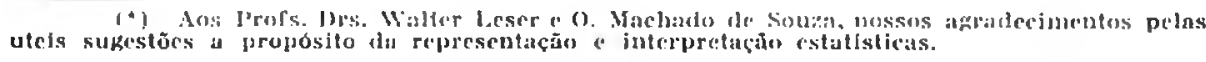


Para interpretar a diferença de $4.39 \mathrm{~cm}$ entre os valores médios deduzidos deste grupo de 164 peças e correspondentes às mensuraçōes efetuadas antes e dejois da fixação, impoz-se a aplicação do "t test", graças ao qual se pôde qualificar a citada diferença como estatisticamente significante. Esta significação é obviamente condicionada à própria fixdção, traduzindo-se, todavia, por indice carecente de maior importância prática.

Por outro lado, determinando-se a porcentagem de retratilidade de cada unma das 164 peças, verifica-se ser a média aritmética da distribuição equivalente a $9.82 \%$ e o seu desvio padrão a $上 4.42 \%$. Por outros têrmos, o cálculo do coeficiente de variabilidade permite decidir da imnossibihidade de se prever o valor teórico que se podcria esperar, caso as 411 peças tivessem sido medidas a fresco. Reciprocamente, como êsse coeficiente de variabilidade, expresso em têrmos de porcentagem de retração, se eleva a cêrca de $45 \%$, demonstra-se, ao mesmo tempo, que os resultados obtidos em material fresco oferecem maior segurança, ou seja, representam mais regular- e precisamente a condição anatômica média.

O Gráfico i dá-nos idéia da distribuição global por freqüências, reunindo-se os 411 valores em classes com amplitude de $3 \mathrm{~cm}$; no mesmo gráfico acha-se também inscrita a curva normal, de forma

\section{QUAIRO I}

Distribuiçero glohal dos valores correspondentes is 411 peças fixadas.

\begin{tabular}{|c|c|c|}
\hline Clinsse's (cmu $\mathrm{cm})$ & .ง." do observaçües & $r$ \\
\hline $25-28$ & 3.0 & 0.73 \\
\hline $23-3.1$ & 21.0 & 5.11 \\
\hline $81-31$ & 36.0 & 8.76 \\
\hline $34-37$ & $6 \overline{3.0}$ & 15.81 \\
\hline $37-40$ & $81 . \overline{1}$ & 10.83 \\
\hline $40-43$ & 51.5 & 17.40 \\
\hline $4: 3-46$ & $54 . \overline{5}$ & 13.26 \\
\hline $46-49$ & $38 . \overline{3}$ & 9.37 \\
\hline $49-52$ & 21.0 & 5.11 \\
\hline$\tilde{0} 2-5 \overline{5}$ & 8.0 & 1.95 \\
\hline $55-58$ & 10.0 & 2.43 \\
\hline \multirow[t]{2}{*}{$58-61$} & 1.0 & 0.24 \\
\hline & 411 & 100.00 \\
\hline
\end{tabular}


a permitir a comparação entre as freqüências desta curva e as correspondentes à distribuição atual. As diferenças, aliás bem pouco apreciáveis, notadas entre os valores encontrados e os teóricos, referentes a cada ordenada, não tem significação sendo, portanto, atribuiveis às flutuações de amostras simples.

A tabulagem dêsses valores atuais, aduzidas as respectivas porcentagens, por classe, em relação ao total, acha-se indicada no Quadro I.

Porlemos concluir, mediante exame do Quadro I e do Gráfico I, que a classe modal é à de $37-40 \mathrm{~cm}$ com 81.5 obscrvações; a meda ou norma dessa classe é igual a $38.57 \mathrm{~cm}$.

A média anotada para as 411 peças, encontrada igual a 40.41 cm, possibilita-nos inferir o número de observaçoes enquadradas na classe que the corresponde: a de 40-43 cm, com 71.5 casos, isto é, $17.40 \%$ do total; como se vê, trata-se de classe na qual não se conta o maior número de peças. O mesmo, diga-se de passagem, sucede em relação à média calculada para o grupo de 164 duodenos medidos após fixação, situàda, anàlogamente, na classe $40-43 \mathrm{~cm}$.

As duas classes 37-40 e 40-43 cm, de maior freqüência, com 153 casos, cnglobam $37.23 \%$ do total de observações; as quatro classes de maior freqüûncia, incluidas entre 34 e $46 \mathrm{~cm}$, com 272.5 peças, representam $66.30 \%$ do total.

Uma apenas, ou seja $0.24 \%$ do total, apresentava a abertura do ducto biliar comum além de $58 \mathrm{~cm}$ a partir do piloro. Sòmente em 3 casos, vale dizer $\mathrm{cm} 0.73 \%$ das observaçôs, tal abertura se localizava a menos de $28 \mathrm{~cm}$ do piloro.

Apresenta particular interêsse a análise da distribuição dos valores correspondentes às medidas de peças a fresco, dentro de classes da mesma amplitude escolhida para os dados provenientes da mensuração de duodenos fixados (Quadro II).

O Gráfico II mostra-nos a representação dos dados correspondentes a êste grupo de peças, nelc também se podendo apreciar as freqüências previsíveis mediante a equação normal de Gauss - Laplace, relativamente a cada ordenada. A menor coincidência entre as curvas experimental e teórica, face ao que se nota no Gráfico I, compreensível por ser menos elevado o número de peças medidas a fresco, é devida únicamente às ílutuações de amostras simples, mesmo para as ordenadas construidas sûbre os pontos médios 42.50 e $45.50 \mathrm{~cm}$.

A distribuição por freqüências, de acôrdo com a tabulagem apresentada no Quadro II, indica como classe modal a de $41-44 \mathrm{~cm}$, com 41.0 peças, sendo a moda equivalente a $42.58 \mathrm{~cm}$. 


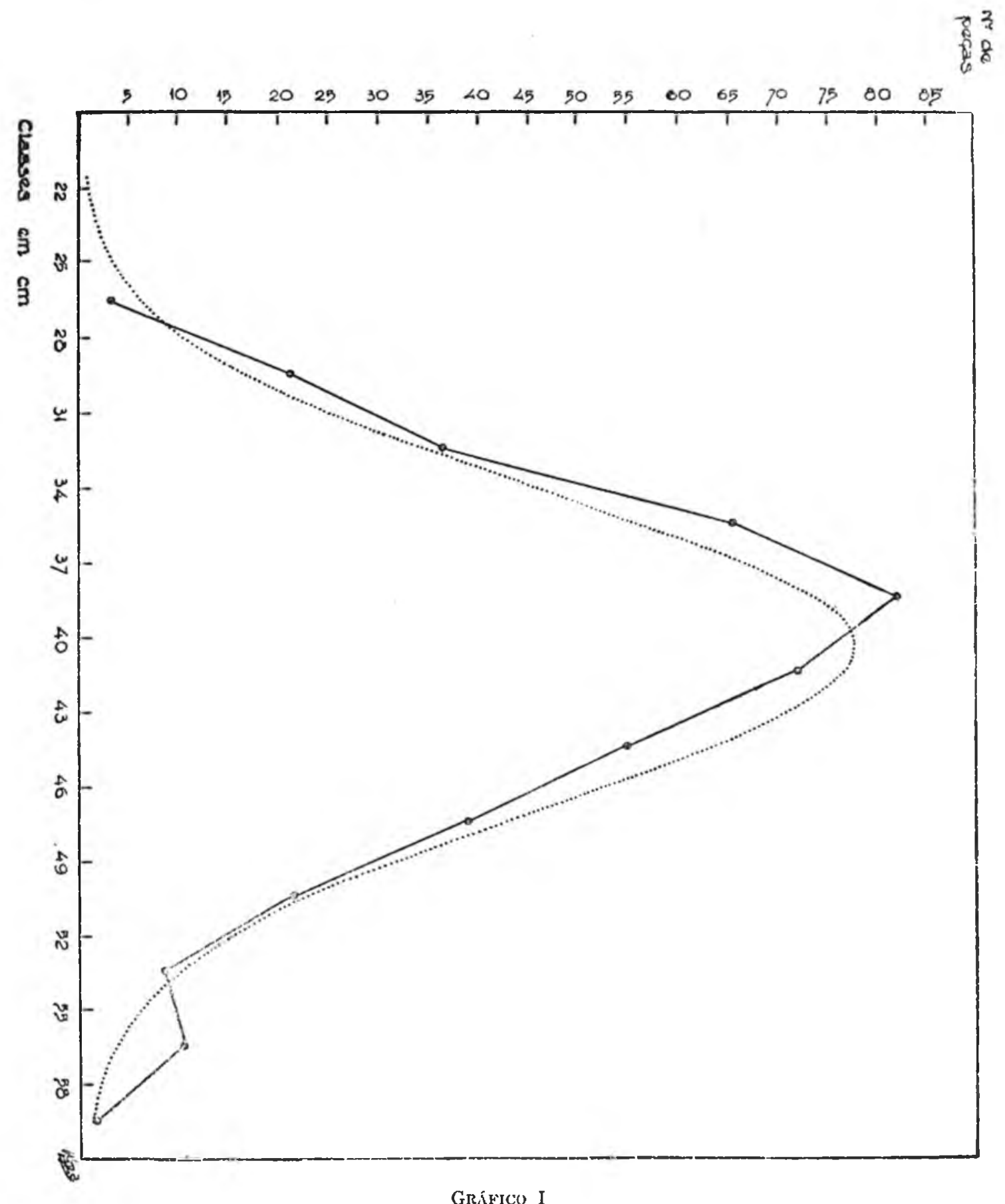

Distribuição por frequiências, correspondente is 411 peças fixadas, acompanhada da respectiva curva normal. 


\section{QUADRO II}

Distribuição dos valores anotados, anteriormente à fixação, no grupo de 164 peças.

\begin{tabular}{c|c|c}
\hline Chusses (em cm) & N.० de observaçoes & \\
& & \\
\hline $32-35$ & 4.0 & 2.44 \\
$35-38$ & 15.0 & 9.15 \\
$38-41$ & 23.0 & 14.02 \\
$41-44$ & 41.0 & 25.00 \\
$44-47$ & 25.5 & 15.55 \\
$47-50$ & 26.0 & 15.85 \\
$50-53$ & 13.0 & 7.93 \\
$53-56$ & 7.5 & 4.57 \\
$56-59$ & 5.0 & 3.05 \\
$59-62$ & 1.0 & 0.61 \\
$62-65$ & 2.0 & 1.22 \\
$65-68$ & 1.0 & 0.61 \\
\hline & 164 & 100.00 \\
\hline
\end{tabular}

QUADRO III

Distribuição dos valores registrados, após a fixação, no grupo de 164 peças.

\begin{tabular}{c|c|c}
\hline Clısses (em cm) & N. de observações & or \\
\hline $28-31$ & 4.0 & 2.44 \\
$31-34$ & 17.0 & 10.37 \\
$34-37$ & 23.0 & 14.02 \\
$37-40$ & 39.5 & 24.09 \\
$40-43$ & 28.0 & 17.07 \\
$43-46$ & 23.0 & 14.02 \\
$46-49$ & 15.5 & 9.45 \\
$49-52$ & 8.0 & 4.88 \\
$52-55$ & 2.0 & 1.22 \\
$55-58$ & 3.0 & 1.83 \\
$58-61$ & 1.0 & 0.61 \\
\hline
\end{tabular}




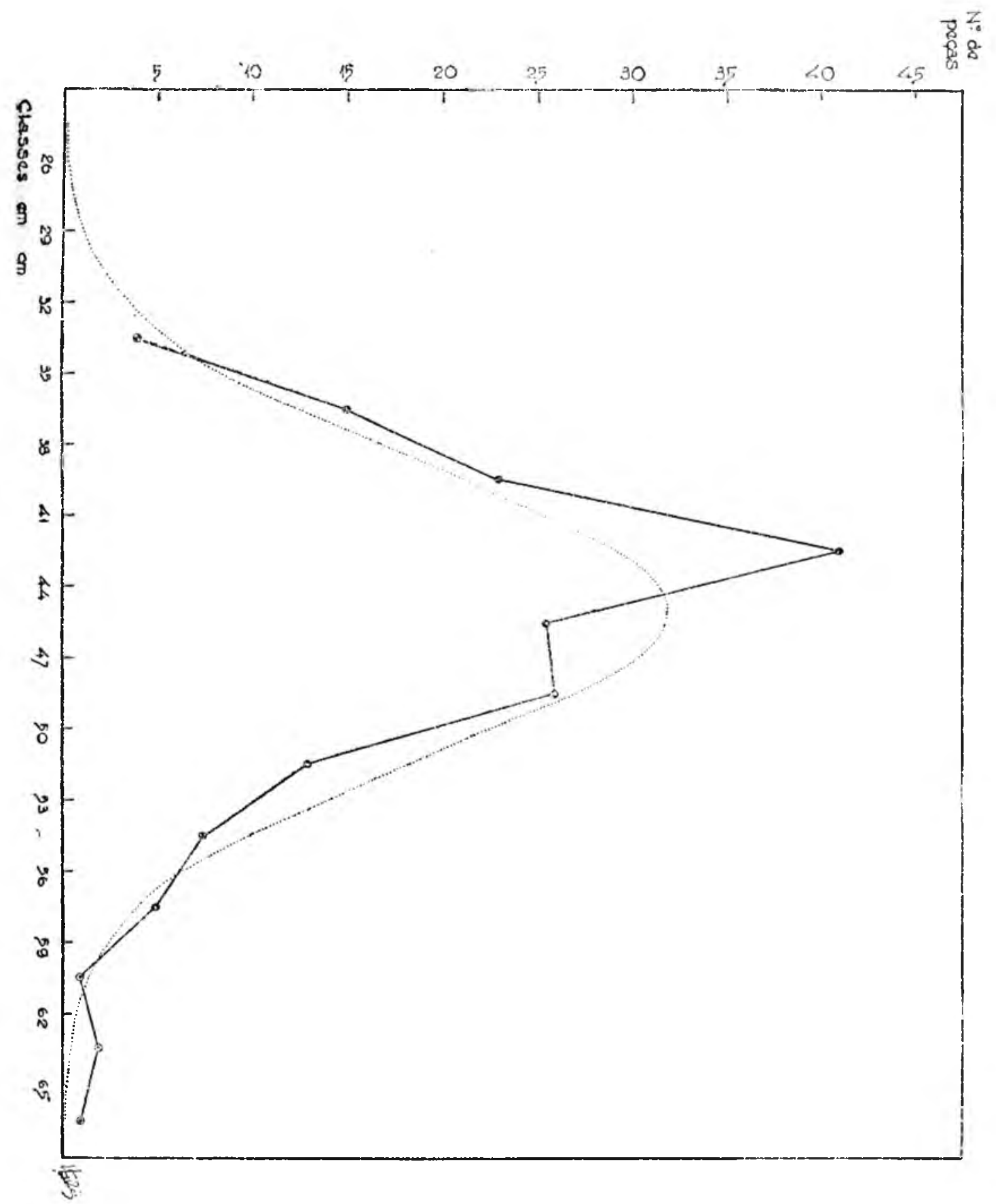

\section{Gráfjeo II}

Distribuição por freqüências, correspondente ao grupo de 164 dundenos não fixados, acompanhada da respectiva curva normal. 
A média determinada nas 164 peças óra classificadas foi, como de início se disse, de $45.02 \pm 0.49 \mathrm{~cm}$. Procurando a classe em que se localiza a média, a classe de $44-47 \mathrm{~cm}$, verifica-se estarem incluidas na mesma 25.5 observaçōes, isto é, $15.55 \%$ do total; assim, a média não coincide com a classe de maior freqüência.

Reunindo-se as duas classes de maior freqüência, 41-44 e 47-50, com 67 observações, agrupa-se $40.85 \%$ do total examinado, enquanto, procedendo da mesma maneira em relação às quatro classes mais numerosas em valores, entre 38 e $50 \mathrm{~cm}$, englobam-se 115.5 observações, ou scja, $70.42 \%$ do total de peças medidas a fresco.

Para efeito de comparação pode-se examinar, no Quadro III, a distribuição por freqüências dos valores correspondentes ao mesmo grupo de peças do Quadro II, decorridas, entretanto, 72 horas de fixação do material.

A falta de qualquer indicação bibliográfica, relatando conclusōes de pesquisa conduzida com o método estatístico, objetivando a determinação da distância, a partir do piloro, a que se acha situada a papila duodenal maior, quer em bovinos de modo geral, quer particularmente em mestiços de Zebu, impossibilita-nos confrontar os resultados obtidos com os de quase todos os outros AA.

BAUMANN e SCHMOTZER, entretanto, além de indicarem os valores limites para a distância do piloro à abertura do ducto colédoco $(50-70 \mathrm{~cm})$, em bovinos de origem provàvelmente européia, apontam os resultados correspondentes a 8 mensurações $(59.0,62.5,68.0,54.5$, $69.5,53.0,52.0$ e $67.0 \mathrm{~cm}$ ), cuja média alcança $60.7 \mathrm{~cm}$. Conhecidas as variáveis, tornou-se viavel o cálculo do desvio padrão e do êrro da média e, conseqüentemente, através a aplicaçāo do "t test", a interpretação da acentuada diferença deduzida das médias estabelecidas por BAUMANN e SCHMOTZER $(60.70 \mathrm{~cm})$ em peças fixadas - umas pela glicerina fenicada e arsênico, outras pelo Kayserling, métodos de fixação que certamente não produzem retração idêntica à determinada pelo formol - e pelos AA. $(45.02 \mathrm{~cm})$ em material fresco.

Os valores em cotejo: $60.70 \pm 2.49 \mathrm{~cm}$ e $45.02 \pm 0.49 \mathrm{~cm}$, prestam-se a que avaliemos a diferença de $15.68 \mathrm{~cm}$ como revestindose de significância estatística.

Também MANN, BRIMHALl e FoSTER, ao estudarem o tracto biliar extra-hepático, em animais domésticos e de laboratório, visando, afora outra questão, verificar se existia relaçāo entre a presença e ausência da vesícula biliar e a distância que separa o piloro do ponto de abertura, no duodeno, do ducto biliar comum, tendo realizado tô- 
das as dimensōes em material fresco, agrupam em tabela os resultados de 5 observações em bovinos, provàvelmente de origem européia. Ora, nas 5 vacas selecionadas, tendo aproximadamente o mesmo tamanho, apresentaram os AA. os seguintes dados para a distância do piloro à abertura do ducto: $500,550,575,575,550 \mathrm{~mm}$, com a média de $550 \mathrm{~mm}$; permitem-nos tais valores, igualmente, o cálculo do desvio padrão e do êrro da média e facilitam-nos a aplicação do "t test", para ajuizar da significância ou não quanto à diferença das médias.

Esses números forneceram os seguintes resultados:

$$
\mathrm{v}=55.00 \pm 1.37 \mathrm{~cm}
$$

A partir dos mesmos, mediante aplicaçāo do "t test", concluimos pela existência de significação, do ponto de vista estatístico, para a diferença de $9.98 \mathrm{~cm}$ entre a média determinada por MaNN, Brimhall e Foster $(55.00 \mathrm{~cm})$ e a deduzida na presente contribuição em peças frescas $(45.02 \mathrm{~cm})$.

Em princípio, poderíamos admitir duas explicações para a diversidade de resultados: $1^{\circ}$ ) - ela seria dependente da adoção de diretrizes de ordem técnica diferentes das que seguimos, concernentes à retirada das peças, tratamento e mensuração das mesmas, envolvendo escôlha diversa de pontos de reparo, etc.; $2 .^{\circ}$ ) - ela seria atribuível a fatores constitucionais correlacionados ao sexo, idade e à raça. Convem discuti-las em separado.

Consignamos devidamente, e muito de engenho, ao tratar do material de estudo, a imprescindivel necessidade de indicar com exatidão o modo de obtenção dos dados. ManN, BRimhall e Foster exprimem também êsse objetivo ao esclarecer que tôdas as dimensões foram praticadas em material fresco e mais, que as medidas, salvo algumas exceçōes, foram tomadas pela mesma pessoa. Destacaram o interêsse em operar com animais de tamanho relativo aproximado, mas relevaram a influência da idade dos animais selecionados, ou, se não o fizeram também não o mencionaram. Deixaram, todavia, de descrever quais os pontos de reparo adotados e omitiram a descrição da técnica de mensuração, fatos de importância capital para ajuizar das eventuais diferenças entre os resultados em cotejo.

Pondo de parte, entretanto, esta hipótese, interessando questão de método, não o faremos por desacreditar na sua intercorrência no estudo comparativo a que se procede, mas por admitir a existência de outro fator, o racial, capaz de atuar e mesmo de se sobrepor aos de ordem técnica, influenciando de maneira essencial e direta a divergência dos resultados óra em discussão. 
Por outro lado, quando se cotejam os dados fornecidos pelos tratadistas e outros AA., agrupados na relação da página 228 - supondo, como é lícito fazer-se, tratar-se de valores estabelecidos através o exame de número ignorado de peças, ou seja, admitindo que cada qual represente a média de uma série de medidas, ainda que pequena - com os deduzidos por nós, chegà-se imediatamente a concluir serem todos os resultados conhecidos para a distância do piloro à abertura do ducto colédoco, mais elevados, em média, do que os verificados em bovinos mestiços de Zebu, reunidos para estudo na publicação óra apresentada.

E' então lógico, busquemos razões, que não ùnicamente de ordém técnica, para compreender a diferença entre a média calculada, relativa à distância do piloro à abertura do ducto biliar, em duodenos pertencentes a bovinos mestiços de Zebu (Bos indicus) e os geralmente conhecidos e divulgados em tratados e publicações especiais, correspondentes a bovinos de origem européia (Bos taurus). Examinemos, pois, os fatores constitucionais.

O número assaz reduzido de fêmeas examinadas, invalida qualquer dedução a propósito da influência do sexo sôbre os índices, pois, o sacrifício de fêmeas na épocá de colheita do material era esporádico.

A idade é também de se considerar como importante condição na interpretação dos resultados; julgamo-la mesmo fator de mais provável atuação, além e aquém de certos limites, comparativamente ao sexual. Por isso, ao escolher animais entre cêrca de 28 meses (pinças já substituidas) e aproximadamente 51 meses (cantos já substituídos) poder-se-ia levantar a objeção, sem dúvida plausível, de que o periodo fôra de desejar-se de menor amplitude.

Contudo, nāo foi fixada arbitràriamente a amplitude de 23 meses, com os limites já indicados, para escôlha do material de estudo; tomamos para orientação os elementos fornecidos pela publicação de AUERnheIMER (in MARTIN), respeitantes às modificações das medidas do intestino dos bovinos a partir do nascimento. Afirma o A. que o comprimento do intestino delgado em bezerros de 1-8 dias ascende a $10.17 \mathrm{~m}$; de 14 dias a 7 semanas atinge a $19.21 \mathrm{~m}$; com 3 meses alcança cêrca de $24 \mathrm{~m}$; aos 6 meses mede $27 \mathrm{~m}$; entre 1 e $11 / 2$ ano aumenta para $34 \mathrm{~m}$ e por fim, em animais completamente desenvolvidos, apresenta de 36 a $45 \mathrm{~m}$ de comprimento. São ainda de AUERNHEIMER as seguintes observações: o comprimento total do intestino em bovinos de 1-8 dias corresponde, em têrmos médios, a $16.25 \mathrm{~m}$, cabendo $86 \%$ ao intestino delgado; de 2-7 semanas tem em média $22 \mathrm{~m}$, dos quais $89 \%$ representam o segmento delgado e, na mesma ordem, os dados subseqüentes são: 3 meses $-28.6 \mathrm{~m}-85 \% ; 6$ meses $-33.2 \mathrm{~m}$ 
$-83 \% ; 1-11 \frac{2}{2}$ ano $-41.1-84 \%$; no adulto, $49.3 \mathrm{~m}$, dos quais $85.5 \%$ representam o intestino delgado.

Segundo AUern HeIMER conclue-se, pois, que o intestino dos bovinos adquire as dimensões definitivas após os 18 meses de idade e, portanto, que além dos 28 meses podemos considerar, dando margem de 10 meses, o intestino dos bovinos como normalmente constituido quanto às suas proporçōes dimensionais. Entretanto, considerandose o índice médio para o comprimento total do intestino $(49.3 \mathrm{~m})$, e atentando para a porcentagem correspondente ao intestino delgado em conjunto $(85.5 \%)$, deduz-se que o comprimento dêste último é aproximadamente de $42 \mathrm{~m}$. Ora, como ao duodeno cabem em média, de acôrdo com os tratadistas, cêrca de $1.05(90-120 \mathrm{~cm})$, ou seja $2.5 \%$ da dimensão do intestino delgado, conclue-se serem despresíveis as eventuais diferenças, calculadas para o tracto duodenal a partir do comprimento total do intestino delgado, acaso existentes em exemplares colocados nos extremos da amplitude de idade escolhida. Além disso, do segmento duodenal só se considerou a distância do ponto pilórico até à papila hepática, vale dizer, apenas se efetuaram mensurações sôbre cêrca de metade dessa porção do intestino delgado.

Outra questão, correlata de certa forma com a idade, deve ser abordada e diz respeito ao pêso relativo dos animais escolhidos para fornecimento do material de estudo. Como se leu, não demos maior atenção ao pêso dos animais destinados ao fornecimento das peças sôbre as quais se tomaram as medidas. Poderíamos, com alguma dificuldade e se êsse fôsse nosso desejo, anotar o pêso dos animais em vida, ou pelo menos, o das carcassas, tal como são enviadas aos centros de distribuição, com o fito de reunir os valores da distância da abertura do ducto biliar comum a partir do duodeno, em classes correspondentes a exemplares de pêso relativo muito vizinho. Sucede, entretanto, que os bovinos utilizados nas pesquisas, não devidamente preparados para qualquer estudo, constituiam-se aos lotes de condições heterogêneas quanto ao estado da engorda; destarte, chegar-se-ia a obter classes numèricamente uniformes, vale dizer, uniformes apenas em aparência. Por estas razões, preferiu-se para seleção do material a examinar o critério "idade" ao do arrolamento por "pêso".

Completando estas considerações de ordem geral, passemos a dedicar atenção à influência do fator racial, face às medidas obtidas. E' fato de observação comprovada experimentalmente (BLACK, SEMPLF e LUSH em colaboração), que os bovinos mestiços de Zebu, apresentam tendência evidente a se alimentar diversas vêzes durante o dia embora o façam de maneira algo parcimoniosa, comparativamente aos animais de outras raças - Hereford e Shorthorn no caso 
- pois, os representantes destas raças tomam alimento, menor número de vêzes, ingerindo, porém, a cada refeição, rações mais copiosas. A mais plausivel explicação para a peculiaridade é-nos oferecida pela menor capacidade dos tractos digestivos dos mestiços de Zebu, admitem os AA.

BLACK, SEMPLE e LUSH analisaram, estatisticamente, as diferenças verificadas quanto a múltiplas caracteristicas, cotejando sempre mestiços de Zebu e animais das raças Hereford e Shorthorn, concluindo por não encontrar diferenças estatisticamente significantes quanto à espessura do couro, comprimento do intestino, pêso do coração, pulmões, baço, timus, encéfalo e outros órgãos. As diferenças em pêso, das cabeças, línguas, caudas, estômagos e intestinos cheios, em área do couro, foram achadas estatisticamente significantes; na parte correspondente aos estômagos e intestinos, os animais não Zebu tinham-nos mais pesados.

A apreciação daqueles $\mathrm{AA}$. referente ao comprimento do intestino, contraria, parcialmente, a hipótese que havíamos formulado e ainda mantemos, na qual correlacionamos a menor distância entre toro pilórico e abertura do ducto biliar, ao menor comprimento do intestino dos bovinos mestiços de Zebu. Torna-se, todavia necessário, e se houver oportunidade buscaremos nós mesmos realizá-lo, confirmar ou infirmar, em estudo comparativo especial e em apreciável número de peças, se as notáveis diferenças anatômicas e fisiológicas de que nos falam BLACK, SEMPLE e LUSH, particularmente quando mencionam "smaller digestive tracts", implicam simplesmente numa diferença de capacidade e de pêso.

Afinal, e o lembrete cabe aqui perfeitamente, BLACK, SEMPLE e Lush trabalharam com bovinos $1 / 2$ sangue Zebu-Hereford e ZebuShorthorn, enquanto, o material de estudo da contribuição óra apresentada, proveio ùnicamente de animais talvez mais de $7 / 8$ ou $15 / 16$ de Zebu.

\section{RESLMO E CONCIJUSŌES}

$\mathrm{Na}$ presente contribuição ao estudo das vias biliares extrahepáticas, em bovinos mestiços de Zebu, procurou-se estabelecer, estatisticamente, a distância que medeia entre o Torus pyloricus e a abertura do Ductus choledochus na Papilla duodeni hepatica. Foram utilizadas 411 peças obtidas no Frigorífico Armour de S. Paulo, Estado de S. Paulo, sendo 312 provenientes de machos, 14 de fêmeas e as restantes 85 pertencentes a animais cujo sexo não pôde ser determinado. A idade dos bovinos fornecedores do material variava entre 28 e 51 meses aproximadamente. 
Seguindo técnica minuciosamente descrita, mediram-se 411 peças, depois de fixadas em solução formolada a $10 \%$, durante 72 horas, tendo sido, entretanto, separados dêste grupo, ao acaso, 164 duodenos sôbre os quais se efetuaram duas mensurações, antes e após a fixação, para cálculo aproximativo da retratilidade. As conclusões são as seguintes:

1) - A Pupilla duodeni hepatica, em 411 peças fixadas, encontrava-se em média a $40.41=0.31 \mathrm{~cm}$ do Torus pyloricus, sendo a amplitude de distribuição de $33.12 \mathrm{~cm}$, limitada pelos valores extremos 25.78 e $58.90 \mathrm{~cm}$, e o coeficiente de variabilidade igual a $15.59 \%$;

2) - No grupo de 164 peças medidas antes da fixação obtevese para a mesma distância a média $45.02 \pm 0.49 \mathrm{~cm}$, estando as observações distribuidas entre os dados extremos 33.10 ( 2 casos) e $67.20 \mathrm{~cm}$, isto é, numa amplitude de variação de $34.10 \mathrm{~cm}$; o coeficiente de variabilidade foi encontrado igual a $13.85 \%$;

3) - Os valores assinalados para êste grupo de 164 peças depois da fixação foram, para a média e respectivo êrro $40.63 \pm 0.48$ $\mathrm{cm}$, para amplitude de variaçāo $29.90 \mathrm{~cm}$ e para limites máximo e mínimo desta, respectivamente, 29.00 e $58.90 \mathrm{~cm}$; quanto ao coeficiente de variabilidade atingiu a $15.21 \%$;

4) - A aplicação do "t test" na interpretação da diferença de $4.39 \mathrm{~cm}$ entre as duas médias estabelecidas no lote de 164 peças, embora destituida de apreciável importância prática, revelou significância do ponto de vista estatístico, sendo atribuivel à fixação pelo formol;

5) - A porcentagem de retratilidade calculada, peça a peça, em 164 duodenos permitiu estabelecessemos a média aritmética e desvio padrão dessa retratilidade: $9.82 \pm 4.42 \%$; o coeficiente de variabilidade determinado, em têrmos de porcentagem de retração, a partir dêsses valores atingiu a cêrca de $45 \%$, demonstrando-se, assim, não só a impossibilidade de prever qual o valor teórico aproximado a se esperar caso as 411 peças tivessem sido medidas a fresco, como também ser aconselhável a medida das peças anteriormente à fixação, pois, os resultados obtidos no material não submetido à ação do formol representam mais regular- e precisamente a condição anatômicat média;

6) - A superposição das curvas de distribuição por freqüências às respectivas curvas normais, referentes ao grupo de 411 peças fixadas (Gráfico I) e ao de 164 peças frescas (Gráfico II) facilitaram-nos a comparação entre os valores atuais $e$ os correspondentes teóricos previsíveis, revelando-nos, outrossim, que as diferenças notadas entre os dados experimentais e normais, em quaisquer dos pontos médios de classe, não são significantes devendo ser atribuidas às flu- 
tuações de amostras simples. A classe modal do primeiro grupo, a de $37-40 \mathrm{~cm}$, engloba 81.5 peças, ou seja, $19.83 \%$ do total; no segundo grupo a classe modal de $41-44 \mathrm{~cm}$, reune 41 peças, isto é, $25 \%$ do total. As modas relativas at êstes grupos foram, respectivamente, 38.57 e $42.58 \mathrm{~cm}$;

7) - A aplicação do "t test" mostrou haver significação estatística para as diferenças de 15.68 e $9.98 \mathrm{~cm}$ existentes entre as médias deduzidas por BAUMANN e SCHMOTZER $(60.70 \mathrm{~cm})$ e por MANN, BRIMHALL e Foster $(55.00 \mathrm{~cm})$, em bovinos de origem européia, e a calculada por nós em peças frescas $(45.02 \mathrm{~cm})$;

8) - Depois de analisar as condiçōes de ordem técnica e os fatores de natureza constitucional correlacionados ao sexo, à idade, ao pêso e à raça, explicando sua interferência na interpretação dos resultados, alvitramos que a menor distância média entre Torus pyloricus e Papilla duodeni hepatica, por nós verificada, face aos dados conhecidos e divulgados através os tratados e publicações especiais, relaciona-se, possivelmente, com o menor comprimento do intestino dos bovinos mestiços de Zebu (Bos indicus) comparativamente aos de origem européia (Bos taurus).

Esta hipótese não é inteiramente invalidada pelas conclusões do trabalho de BLACK, SEMPLE e LUSH, respeitantes à não significação estatística para a diferença em comprimento de intestino, notada entre mestiços de Zebu e animais das raças Hereford e Shorthorn. De resto, aquêles AA. afirmam que os tractos digestivos dos mestiços são menores e é preciso comprovar, em material numérica - e qualitativamente adequado, se a diferença é simplesmente de capacidade e de pêso; além do mais, há que considerar terem BLACK. SEMPLE e LUSH trabalhado com animais $1 / 2$ sangue Zebu, enquanto operámos com animais talvez mais de $7 / 8$ ou $15 / 16$ de Zebu.

\section{SLMMARY AND CONCLUSIONS}

In this contribution to the study of the extru-hepatic biliary tracts of Brahman crossbreds, was established statistically the disfance from the Torus pyloricus to the opening of the bile duct in the Papilla d uodeni hepatica.

Measurements were made on 411 pieces obtained in the Frigorifico Armorur at São Paulo, Sāo Paulo State, Brasil, of which 312 pertaining to males, 14 to females and the rest to animals that the $A A$. had no chance to determinate the sex. The age range of the cattle us aproximately from 28 (change of the first incisor) to 51 months (change of the fourth incisor). 
Rev. Fac. Med. Vet. S. Paulo - Vol. 3, fasc. 4, 1948

$A$ detailed description of the followed technique is given to show how the measures were taken on 411 duodenal tracts after fixation in a 10 per cent aqueous solution of formuldehyde; 164 of these tracts were separated by chance in order to find rby means of two measures, before and after fixation), the percentage of retractility.

The conclusions can be summed up into:

1) The Papilla duodeni hepatica in 411 fixed pieces was located at $40.41 \pm 0.31 \mathrm{~cm}$ caudud to the $T$ or $u s p y l o-$ $r i c u s$; the range of the values varied from 25.78 to $58.90 \mathrm{~cm}$ and the coefficient of variation was $15.59 \%$;

2) On fresh material, a group of 164 duodenal tracts, the arithmetic mean and its standard error were $45.02 \pm 0.49 \mathrm{~cm}$; the range of the values was from 33.10 (2 cases) to $67.20 \mathrm{~cm}$ and the coefficient of variation was $13.85 \%$;

3) The data obtained for this group of 164 pieces after fixation were $40.63 \pm 0.48 \mathrm{~cm}$ (mean and standard error of it) the range of the values was from 29.00 to $58.90 \mathrm{~cm}$ and the coefficient of variation was $15.21 \%$;

4) The difference of $4.39 \mathrm{~cm}$ between the two means calculated in the group of 164 pieces though without pratical importance, revealed statistical significance and must be attributed to the fixation;

5) The percentage of retractility calculated, piece by piece, in 164 duodenal tracts allowed to establish the arithmetic mean and standard error of this retractility: $9.82+4.42 \%$; the coefficient of variation determined, in terms of percentage of retractility, from these vulues reaches $45 \%$. Thus it seems demonstrating the impossibility of obtaining the theoric value expected if all the pieces had been measured before fixation, as well as, those measures taken on fresh material represent more regularly and precisely, the average anatomic condition:

6) The superposition of both, the frequency distributions and normal curves concerned in the group of 411 pieces (Graph I) and the group of 164 pieces (Graph II) showed through the $X^{2}-$ test that the disparity between experimental and normal frequencies must be ascribable to chance. The modal class in the first group, from 37 to $40 \mathrm{~cm}$, contains 81.5 items, i. e., $19.83 \%$ of all data; in the second group the modal class, from $41-4.4 \mathrm{~cm}$, contoins 41 items, i. e., $25 \%$ of all data. The values of the modes in these tho groups were 38.57 and $42.58 \mathrm{~cm}$ respectively:

7) The differences of 15.68 and $9.98 \mathrm{~cm}$ between the arthmetic means found by BAUMANN and SCHMOTZER $(60.70 \mathrm{~cm})$ and by MANN, BRIMHALL and FOSTER $(55.00 \mathrm{~cm})$ and the calculated by the $A A$. 
(4.5.02 cm), on fresh material, must be considered of statistical significance:

8) After analysing the conditions of technical order and constitutional nature conccrning sex, age, weight and bread of cattle, giving an explanation about the interference of these factors in the interpretation of the results, it is presumed that the shorter distance from To\% s p yloricus to the Papilla duodeni hepatica in Brahman rrossbreds as compared with non-Brahman cattle is connected with the lesser lenght of intestines in the former.

This assumption is not invalidated by the conclusion of BLACK. SEMPLF and LUSH when saying that no statistically significant differences were found in intestine lenght of crossured Brahman-Hereford and Brahman-Shorthorn cattle compared with typical Hereford and Shorthorn cattle. After all those AA. point out as noteworthy physiological and anatomical differences that the Brahman crossbreds had smaller digestive tracts and we think must be confirmed both on numerical and qualitative adequate material if the difference is merely of capacity and weight; besides it should be emphasized that BLACK, SEMPLE and LusH used Brahman-Hereford and Brahman-Shorthorn cattle and we used perhaps, more than $7 / 8$ or $15 / 16$ Brahman crossbreds.

\section{BIBLIOGRAFIA}

BAUMANN, A. - SchMotzer, B. - 1912 - Beiträge zur vergleichenden Anatomie des Vater'schien Divertikels und der Mündung der Gallen- und Pankreasgänge. dsterr. Woch. Tierheilk., 37 (47): 469-71; (48): 479-81; (51): 523-4

Black, W. H. - SEMPLE, A. T. - I.USH, J. I. - 1934 - Beef production and quality as influenced by crossing Brahman with Hereford and Shorthorn cattle. U. S. Dep. Agric., Tech. Bull., 417

Brunni, A. C. - 7. 7mmerl, U. - 1947 - Anatomia degli animali domestici. 2 Milano, Francesco Vallardi

Caradonna, G. B. 1929 - "in" Zimmert, U. - Trattato di Anatomia Veterinaria. 2 Milano, Francesco Vallardi

Chiefl, A. - Paiva, O. M. - Verga, J. S. - 1948 - Contribuição para o estudo da cronologia dentíria no Zebu. Rev. Fur. Mcet. Vet., Săo Paulo, 3 (4): 251-ris

1.FidiRAT!, 1. O. - 1938 - las vias biliales extrahepaticas del hovino y sus variaciones. An. Fac. Med. Vet., I,a Plata. 1 (1): 37-17.

Fatı, P'. - 1935) - Leber und Bauchspeicheldrüse des Wildschweines. Amut. A nz., $79(16 / 20): 321.50$

Blibenafroer, W. - Baum, H. - 1932 - Handbuch der vergleichenden Anatomie der Irastiere. 17 Auf. Berlin, Julius Springer

Favilobi, N. - 192:3 - I'Anatomia del fegato nei principali animali domestici (Cavallo, bue, maiale, cane). Pisa. Tip. A. Cesari 
Favilli, N. - 1931 - Nozionj comparate di Anatomia e Fisiologia degli animali rurali. Torine, Unione Tipografico-Editrice Torinese

Gonzílez y Garcia, J. - Álvarez, R. G. - 1929 - Anatomía comparada de los animales domésticos. 3." ed. Zaragoza, "La Académica"

Higains, G. M. - 1927 - The extrahepatic biliary tract in the guinea-pig. Anat. Rec., 36 (2) : 129-47

LFPoltre, I. - 1921 - Notes du cours d'A natomie comparie des animaux domestiques. Gembloux, J. Duculot

Isesbre, F. X. - 1922 - Précis d'A natomic comparée des animaux domestiques. 1 Paris, J.-B. Baillière et fils

MaNN, F. C. - BRTMhall, S. D. - Foster, J. P. - 1920 - The extrahepatic biliary tract in common domestic and laboratory animals. Anat. Rec., 18 (1) : 47-66

ManN, F. C. - Foster, J. P. - Brimhali, S. D. - 1920 - The relation of the common bile duct to the pancreatic duct in common domestic and laboratory animals. Jour. Lab. \& Clin. Med., 5 (4): 203-6

Martin, P. W. - Scilatufie, W. - 1935 - Lehrbuch der Anatomie der Haustiere. 3 (2). 3 Auf. Stuttgart, Schickhart \& Ebner

Mongiarorio, T. - 1903 - Trattato di Anatomia topografica dei mammiferi domestici. Torino, Luigi Delgrosso

Montané, L. - Bourdelle, E. - 1917 - Anatomie régionale des animaux domestiques. 2 Paris, J.-B. Baillière et fils

RAutmanN, H. - 1921 - Untersuchungen über die Norm. Ihre Bedeutung und Bestimmung. Veröffentlichungen aus der Kriegs- und Konstitutionspathologie, 6 H., 2 (2) Jena, Gustav Fischer

SchäPPI, E. -- 1931 - Magen und Darm des Wildschweines. V: Beitrag zur makroskopischen Anatomie von "Sus scrofa" L. und zum domestikations problem. Inaugural-Dissertation, Zür.ich. Berlin, Julius Springer

Silva Pinto - 1938 - La morphologic des voies biliaires du chien. Ann. Anat. Path., 13 (5): 563-8

Sisson, S. - 1933 - Anatomía de los animales domésticos. Barcelona, Salvat editores, S. A.

Sisson, S. - Grossman, J. D. - 1945 - The Anatomy of domestic animals. ird ed. Philadelphia, W. B. Saunders Company

Stevenson, P. II. - 1921 - The extrahepatic biliary tract of the camel. Anat. Rec., 22 (1) : 85-95

Tномson, S. C. - 1940 - Musings on the biliary tract. Amer. fener. Sury., 47 (?): 687-90

Thomson, S. C. - 1940 - Studies of the Anatomy of the extrahepatic hiliary tract in mammalia. Zool. Ser. Field Mus. Nat. Hist., 22 (6) : 415-30

THomson, S. C. - 1938 - The extrahepatic biliary tract of the "Hyrax". Anal. Rec., 72 (4) : 445-9 